UDC 004.7:679.76

Original Scientific Paper

\title{
Comparison of DPSK and RZ-DPSK Modulations in Optical Channel with Speed of 10 Gbps
}

\section{Petr Ivaniga}

Department of Information Networks, Faculty of Management Science and Informatics, University of Žilina, Slovakia

\section{Tomáš Ivaniga}

Department of Electronic and Multimedia Communications, Faculty of Electrical Engineering and Informatics, University of Technology Košice, Slovakia petr.ivaniga@fri.uniza.sk

tomas.ivaniga@tuke.sk

\begin{abstract}
This article is devoted to the problematic of error rate and modulations in optical communication. Optic waveguide shows insufficiencies in high speed transfers manifested by corrupted transfer. Although modern technological processes contributed to lowering these insufficiencies, it would be uneconomical to completely reconstruct the optical network infrastructure. The solution is only partial so we approach more economical methods, such as modulations. The article works with a 10 Gbps channel with two modulation types, namely DPSK (Differential Phase Shift Keyed) and RZ-DPSK (Return to Zero-Differential Phase Shift Keyed). These modulations are evaluated and compared according to BER (Bit Error Rate) and Qfactor.
\end{abstract}

Keywords: BER, DPSK, RZ-DPSK, Q-factor, SNR

\section{Introduction}

The baseband transmission is insufficient due to an imperfection of optical transmission systems, and increasing requirements for its transmission. The deployment of new hardware devices would be neither technically feasible nor costeffective. Therefore, the signal conditioning was used to make it resistant towards most damaging impacts of optical systems, and to withstand the required task load [1], [2]. There are several possible modulations, each with different characteristic parameters [3]. Because every transfer route has different parameters it is necessary to know which modulation is the most appropriate to maximise effectivity for data transfer.

This article deals with modulations for optical transfer systems of DPSK and RZ-DPSK. 


\section{Eye Diagram}

Eye diagram is a useful tool for quantitative signal analysis used for digital transfers [4]. It offers a view/perspective/platform for evaluation of system's transfer characteristic. It can be used for diagnosis of channel errors [5]. Eye diagram is connected with term as channel BER or SNR (Signal to Noise Ratio).

The correct shape of eye diagram should contain all options of bit sequence. Based on them we can diagnose system's errors. Example of creation of eye diagram is in Figure 1.

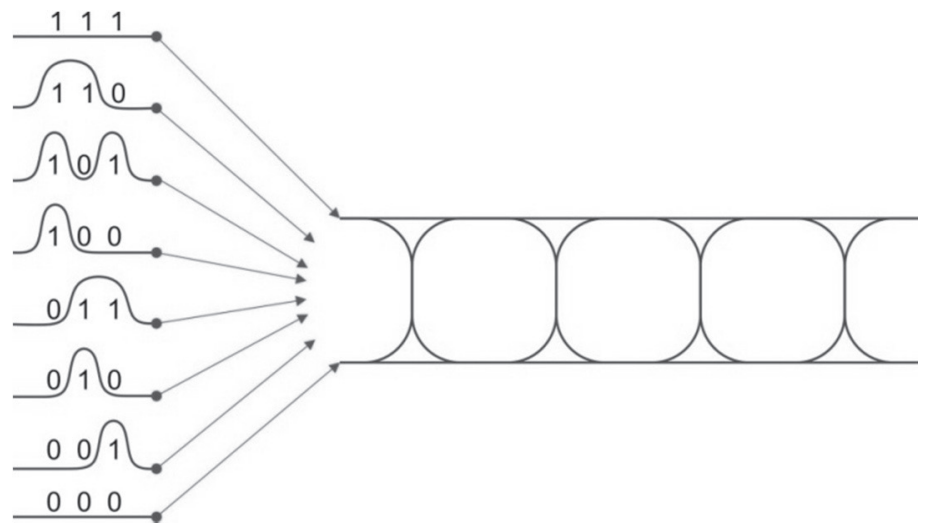

Figure 1 Example of creation of eye diagram

\subsection{Bit Error Rate}

In the case when interference/noise overruns the decisive limit, the symbols get erroneously interpreted and the error occurs. Multiplicity of these errors is described by channel BER. BER is a criterion of quality of digital transfer tracts [6], [7] and [11]. BER can be calculated by a relatively simple method based on error multiplicity in received bit symbols. If we know the number of errors, the BER is expressed as

$$
B E R=\frac{N_{E}}{N_{A}},
$$

where $N_{E}$ is a number of error bits, $N_{A}$ is a number of all transferred bits. Calculating the number of errors can be a lengthy process because of low values $\left(\mathrm{BER}<10^{-12}\right)$ [8], [18]. Calculating BER then becomes complicated and time consuming. Model case of BER calculation is a channel with AWGN (Additive White Gaussian Noise). Channel AWGN can be summed up by an equation

$$
S_{\text {out }}(t)=S_{\text {in }}(t)+n(t)
$$

where $S_{\text {out }}(t)$ is output signal, $S_{\text {in }}(t)$ is input signal and $n(t)$ is the white noise. AWGN explained: "additive" means the noise is added, "white" that it has constant 
spectral power density and "Gaussian" that its amplitude distribution is normal [9], [10] and [11]. BER is in relation to Q-factor. Q-factor is obtained from subtracting the optimal value from average value of logic one limit and from the average value of logic zero limit (Figure 2).

$$
Q=\frac{\mu_{1}-\gamma_{o p t}}{\sigma_{1}}=\frac{\gamma_{o p t}-\mu_{0}}{\sigma_{0}}=\frac{\mu_{1}-\mu_{0}}{\sigma_{1}+\sigma_{0}}
$$

where $\gamma_{o p t}$ is optimal value. Optimal value $\gamma_{o p t}$ can further be expressed as

$$
\gamma_{o p t}=\frac{\sigma_{0} \mu_{1}-\sigma_{1} \mu_{0}}{\sigma_{1}+\sigma_{0}}
$$

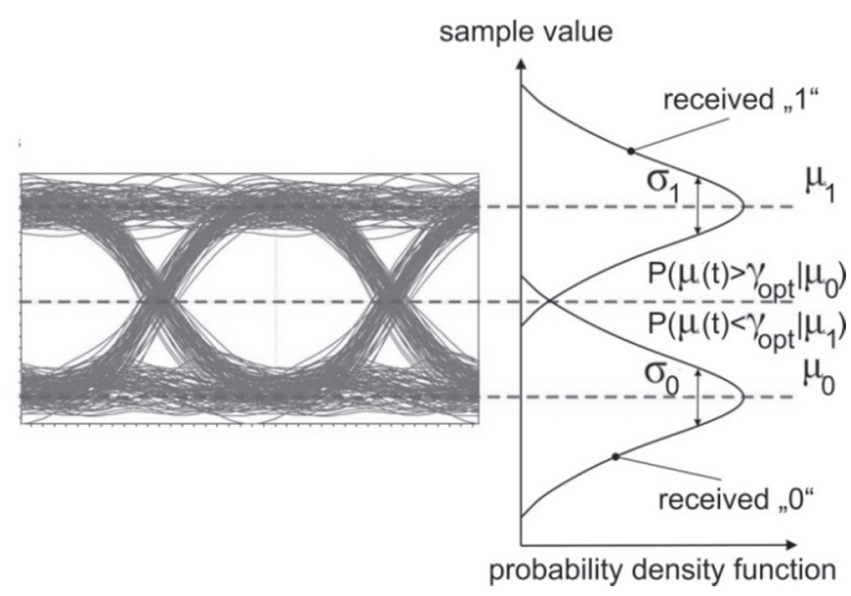

Figure 2 Probability density of BER

Probability density of BER $P\left(\mu(t)>\gamma_{o p t} \mid \mu_{0}\right)$ from Figure 2 gives the value when probability $\mu(t)$ is bigger than optimal value or average value of logical zero limit. Probability density of BER $P\left(\mu(t)<\gamma_{o p t} \mid \mu_{1}\right)$ from Figure 2 gives the value of probability $\mu(t)$ that is smaller than optimal value of average value of logical one limit.

As a consequence of overlapping of these two areas a problem arises whether it is here "0" or "1" [12], [17]. The decision can be made based on probability separately for logical zero and separately for logical one according to these equations

$$
\begin{aligned}
& P(1 \mid 0)=\frac{1}{\sigma_{0} \sqrt{2 \pi}} \int_{\gamma_{o p t}}^{\infty} e^{-\frac{1}{2} \cdot\left(\frac{\mu-\mu_{0}}{\sigma_{0}}\right)^{2}} d \mu=\frac{1}{2} \operatorname{erfC}\left(\frac{\gamma_{o p t}-\mu_{0}}{\sigma_{0} \sqrt{2}}\right), \\
& P(0 \mid 1)=\frac{1}{\sigma_{1} \sqrt{2 \pi}} \int_{\gamma_{o p t}}^{\infty} e^{-\frac{1}{2} \cdot\left(\frac{\mu-\mu_{1}}{\sigma_{1}}\right)^{2}} d \mu=\frac{1}{2} \operatorname{erfC}\left(\frac{\mu_{1}-\gamma_{o p t}}{\sigma_{1} \sqrt{2}}\right) .
\end{aligned}
$$

From presented equations BER is expressed and the result is 


$$
B E R=\frac{1}{2}[P(1 \mid 0)+P(0 \mid 1)]=\frac{1}{4}\left[\operatorname{erfc}\left(\frac{\gamma_{o p t}-\mu_{0}}{\sigma_{0} \sqrt{2}}\right)+\operatorname{erfc}\left(\frac{\mu_{1}-\gamma_{o p t}}{\sigma_{1} \sqrt{2}}\right)\right],
$$

from which it can be concluded that

$$
B E R=\frac{1}{2} \operatorname{erfc}\left(\frac{Q}{\sqrt{2}}\right) \approx \frac{e^{\left(-\frac{Q^{2}}{2}\right)}}{Q \sqrt{2 \pi}}
$$

Channel BER is different for every modulation signal. It depends also on the transfer speed [1], [13]. For transfer speed of $40 \mathrm{Gbps}$ it must be at least BER $=10^{-12}$.

\subsection{Signal to Noise Ratio}

BER is also connected with SNR which is defined as a measure of signal power $\left(P_{S}\right)$ to noise $\left(P_{N}\right)$ [14]. Horizontal part of eye diagram marks the interval from noise

$$
S N R=\frac{P_{S}}{P_{N}}
$$

If a signal containing noise component amplifies, both parts will be amplified. There may be situations where you cannot recognize the signal due to the high level of amplified noise components. SNR can be expressed in BER

$$
B E R=\frac{1}{2} \operatorname{erfc}\left(\frac{S N R}{2}\right)
$$

BER depends on the transmission rate. It is different for each modulation signal. If BER decreases, the SNR value increases and there is a better transmission over an optical channel [15], [16]. If DGD value increases and the value of SNR decreases, the eye diagram is closed in horizontal and vertical direction. The value that closes the eye diagram is called Power Penalty. Figure 3 shows the dependence of BER on SNR.

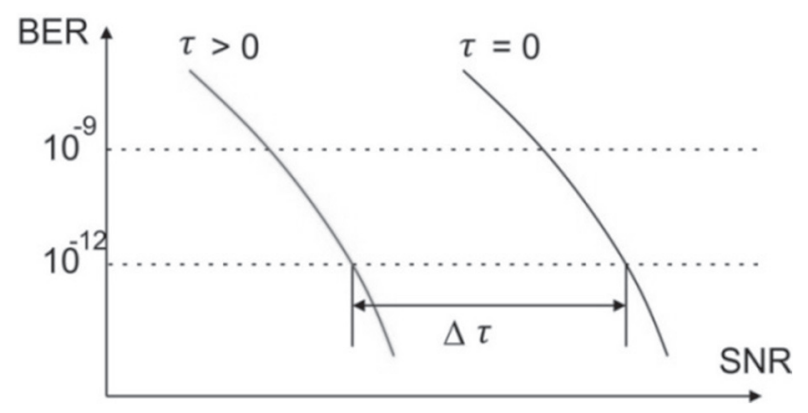

Figure 3 Drop in eye diagram 


\section{Modulation in Optical Networks (DPSK, RZ-DPSK)}

The interest in modulation formats due to the large distances between transmission lines and requirements on transmission quality is huge [17]. It is very advantageous, but also necessary, appropriately modulate the signal before being adjusted by transmission.

There are two basic types of modulation. The first group is an analog modulation where the modulating signal varies continuously over time [18], [19]. Among analog modulations belong amplitude modulation, frequency modulation and phase modulation. The second group is a digital modulation. The modulation signal is a discrete signal, most often in the form of a bit sequence. In the context of digital modulation, we are talking about keying. There is a variety of digital modulation formats. The basic modulation format used in optical networks is amplitude modulation ASK (Amplitude Shift Keying) or OOK (On-Off Keying).

Furthermore, phase modulation PSK (Phase Shift Keying) and modulation NRZ (Non-Return-To-Zero) without return value to zero. With increasing demand for higher transmission capacity, the modulation CSRZ (Carrier-Suppressed RZ) was developed, then the modulation CRZ (Chirped RZ), which is a special case of modulation of RZ (Return-To-Zero) with the return value to zero. Other modulations used include quadrature amplitude modulation QAM (Quadrature Amplitude Modulation) or frequency shift keying FSK (Frequency Shift Keying).

As it results from PSK definition optical bit stream is generated by the change of bearing phase. During this change the amplitude and frequency of optical bearing remain constant. In the case of binary PSK (BPSK) the phase can have two values, usually 0 and $\pi$. One of the consequences of PSK modulation is that the light intensity during the transfer of bit stream remains constant. For that reason the so called direct detection receivers cannot be used to detect PSK signals [20], [25]. Additive demodulation is necessary and some form of coherent detection equipment needs to be applied. In the case of DPSK data is transferred by bearing phase difference between two adjacent bits. If the previous bit was of value 0 , the coding of the current bit does not use a phase displacement. In the opposite case if the previous bit was of value 1 , bearing phase changes by $180^{\circ}$ while transferring the current bit.

With RZ-DPSK modulation RZ impulse is being modulated instead of CW signal - the optical impulse is in every bit slot and is decoded as a phase displacement 0 or $\pi$ between adjacent bits [21], [22]. Contrary to PSK, where the detection methods try to be exact with bearing phase, with DPSK the demand is not so high on the dispersion bearing [23], [24]. Because the bearing phase difference of received adjacent bits is all that is needed to obtain transferred information, it is sufficient if the bearing one is more or less stable for the duration of two bits.

The majority of optical communicating systems use conventional OOK signals. But a situation can occur when DPSK or RZ-DPSK modulations achieve better results. For example, compared to a standard RZ the RZ-DPSK modulation achieves via amplitude modulation roughly $3 \mathrm{~dB}$ higher values of SNR ratio because of the presence of optical impulse in every bit slot. 


\section{Simulation of 10 Gbps for DPSK and RZ-DPSK Comparison}

A topology was created for the purpose of comparing the modulations DPSK and RZ-DPSK.

The whole topology consists of three parts (Figure 4): transmitting part, network part and receiver part. The transmitting part contains: Laser (CW, ML), Bit Pattern Generator, Electrical Signal Generator and Phase Modulator. The bit pattern generator is set for $10 \mathrm{Gbps}$, a phase modulator has a set deviation of 180 degrees. For the depiction of modulations we used two lasers.

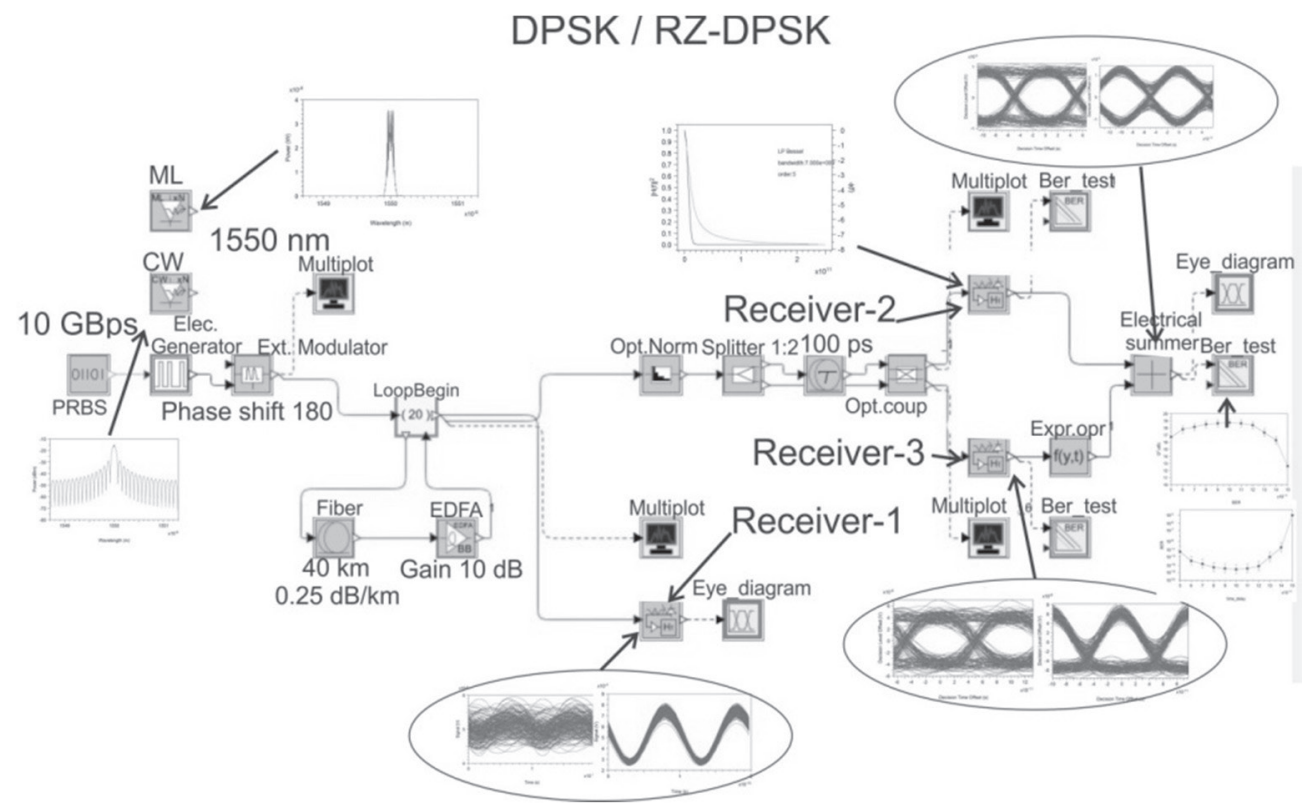

Figure 4 Topology for comparison of modulations

The difference between two topologies is in a different DPSK connection. In the DPSK case we used CW Laser as a source of optical signal whereas the RZ-DPSK connection used Mode-Locked Laser as its source of optical signal which generates the sequentiality in repeating cosine $\mathrm{RZ}$ pulses of speed equal to the bit speed. $\mathrm{CW}$ laser and ML-laser have a peak power set on $0.5 \mathrm{~mW}$ and wavelength on $1550 \mathrm{~nm}$. Behind the transmitting part there are 20 loops with $40 \mathrm{~km}$-long optical fibre with attenuation $0.25 \mathrm{dBkm}^{-1}$ and EDFA amplifier with gain $10 \mathrm{~dB}$.

DPSK eye diagram before demodulation is depicted in Figure 5 on the left. It can be observed that the optical signal is of constant intensity and so in both cases the data cannot be detected by IM/DD receiver.

To demodulate the signal we used a Mach-Zehnder delay interferometer. An optical splitter divides optical signal in 1:2 ratio. Different time delay is set by bit lasting $100 \mathrm{ps}$ for receiver 2. Two outputs correspond to two ports. Maximal output is seen on the first port when the phase change is not between adjacent bits and on the 
second port when the phase of adjacent bits differs by $\pi$. Values taken from the port of receiver 2 for DPSK and RZ-DPSK are in Table 1 and in Figure 6.

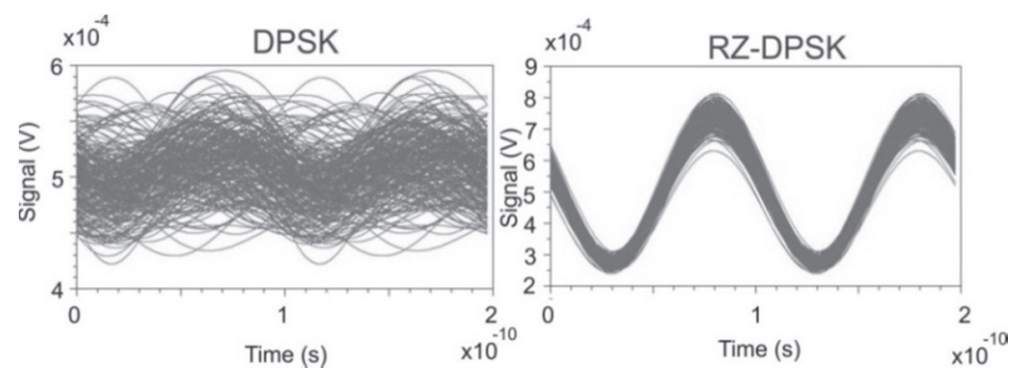

Figure 5 DPSK and RZ-DPSK after going through 20 spans

\begin{tabular}{|c|c|c|c|c|}
\hline Modulation & BER & BER lo & BER hi & Q $^{\mathbf{2}}(\mathbf{d B})$ \\
\hline $\boldsymbol{D P S K}$ & $9.1404^{-9}$ & $1.0853^{-9}$ & $7.6126^{-8}$ & 15.006 \\
\hline $\boldsymbol{R} \boldsymbol{Z}$-DPSK & $4.8131^{-14}$ & $1.6949^{-15}$ & $1.1558^{-12}$ & 17.438 \\
\hline
\end{tabular}

Table 1 Receiver 2

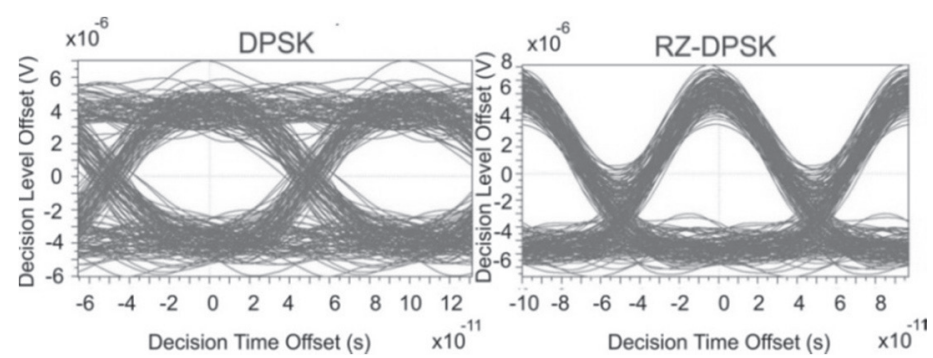

Figure 6 Comparison of DPSK and RZ-DPSK with time delay of $100 \mathrm{ps}$

Measured values for receiver 3 without time delay are in Table 2 and portrayed in Figure 7.
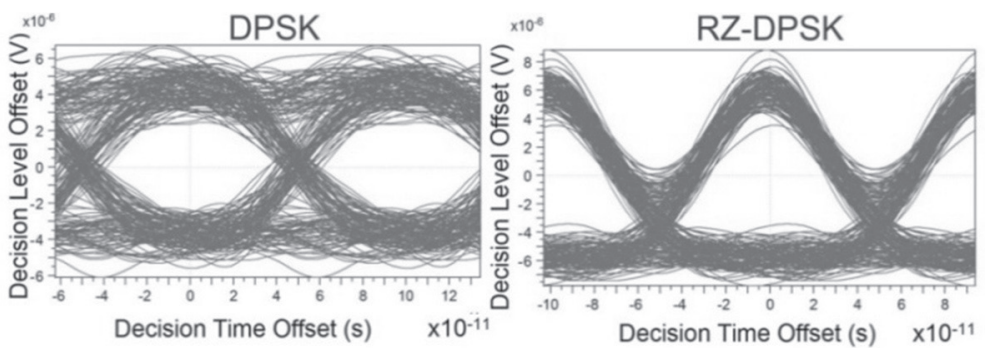

Figure 7 Comparison of DPSK and RZ-DPSK without time delay 100 ps 


\begin{tabular}{|c|c|c|c|c|}
\hline Modulation & BER & BER lo & BER hi & $\mathbf{Q}^{2}(\mathbf{d B})$ \\
\hline DPSK & $1.2870^{-8}$ & $2.1653^{-9}$ & $7.0004^{-8}$ & 14.914 \\
\hline $\boldsymbol{R Z}$-DPSK & $7.9110^{-14}$ & $1.6334^{-15}$ & $3.0830^{-12}$ & 17.361 \\
\hline
\end{tabular}

Table 2 Receiver 3

Resulting electrical signals from receivers are combined by Electrical Summer. The end results are in Table 3 and in Figure 8.

\begin{tabular}{|c|c|c|c|c|}
\hline Modulation & BER & BER lo & BER hi & $\mathbf{Q}^{2}(\mathbf{d B})$ \\
\hline $\boldsymbol{D P S K}$ & $2.4800^{-18}$ & $3.0445^{-20}$ & $1.8177^{-16}$ & 18.745 \\
\hline $\boldsymbol{R} Z$ - $\boldsymbol{D P S K}$ & $6.8326^{-27}$ & $6.7953^{-30}$ & $4.7689^{-24}$ & 19.007 \\
\hline
\end{tabular}

Table 3 Result values added up by Electrical summer

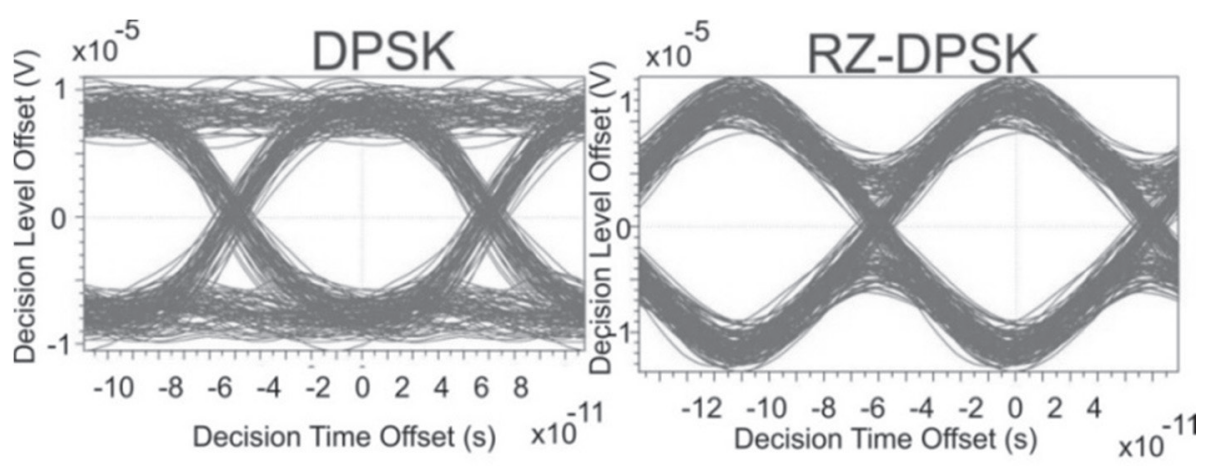

Figure 8 Result values of BER for DPSK and RZ-DPSK

\subsection{Simulation for Comparison of BER and Q-factor with increment $10 \mathrm{ps}$}

Second simulation was created to compare BER and Q-factor for DPSK and RZDPSK. In this simulation the time delay changed to increment of $10 \mathrm{ps}$ for 11 iterations. The end dependencies of BER and Q for DPSK are in Table 4 in the graph in Figure 9.

\begin{tabular}{|c|c|c|c|c|}
\hline $\begin{array}{c}\text { Time delay } \\
{[\mathbf{p s}]}\end{array}$ & BER & BER lo & BER hi & $\mathbf{Q}^{\mathbf{2}}(\mathbf{d B})$ \\
\hline 50 & $3.2643^{-12}$ & $2.0154^{-13}$ & $4.8667^{-11}$ & 16.736 \\
\hline 60 & $4.5596^{-15}$ & $1.2817^{-16}$ & $1.4406^{-13}$ & 17.787 \\
\hline 70 & $3.6500^{-16}$ & $7.5946^{-18}$ & $1.5578^{-14}$ & 18.133 \\
\hline 80 & $1.7161^{-17}$ & $2.7616^{-19}$ & $9.9545^{-16}$ & 18.517 \\
\hline 90 & $5.5903^{-18}$ & $7.5562^{-20}$ & $3.6462^{-16}$ & 18.651 \\
\hline 100 & $2.4800^{-18}$ & $3.0445^{-20}$ & $1.8177^{-16}$ & 18.745 \\
\hline 110 & $5.6617^{-18}$ & $7.4555^{-20}$ & $3.8927^{-16}$ & 18.649 \\
\hline
\end{tabular}




\begin{tabular}{|l|c|c|c|c|}
\hline 120 & $5.2754^{-17}$ & $8.1790^{-19}$ & $3.0611^{-15}$ & 18.380 \\
\hline 130 & $9.0414^{-14}$ & $3.0458^{-15}$ & $2.3262^{-12}$ & 17.340 \\
\hline 140 & $4.0107^{-11}$ & $2.7817^{-12}$ & $5.1317^{-10}$ & 16.259 \\
\hline 150 & $9.5199^{-6}$ & $3.0761^{-6}$ & $2.7852^{-5}$ & 12.620 \\
\hline
\end{tabular}

Table 4 Result values of BER and Q-factor with increment 10 ps for DPSK

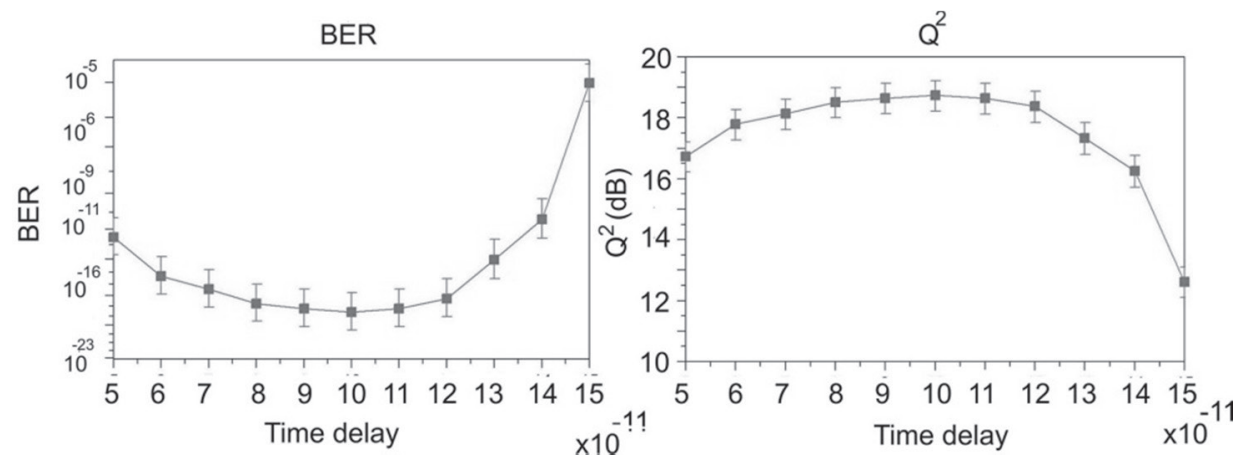

Figure 9 Comparison of BER and Q-factor for DPSK with increment 10 ps

Resulting dependencies BER and Q for RZ-DPSK are in Table 5 and in the graph in Figure 10.

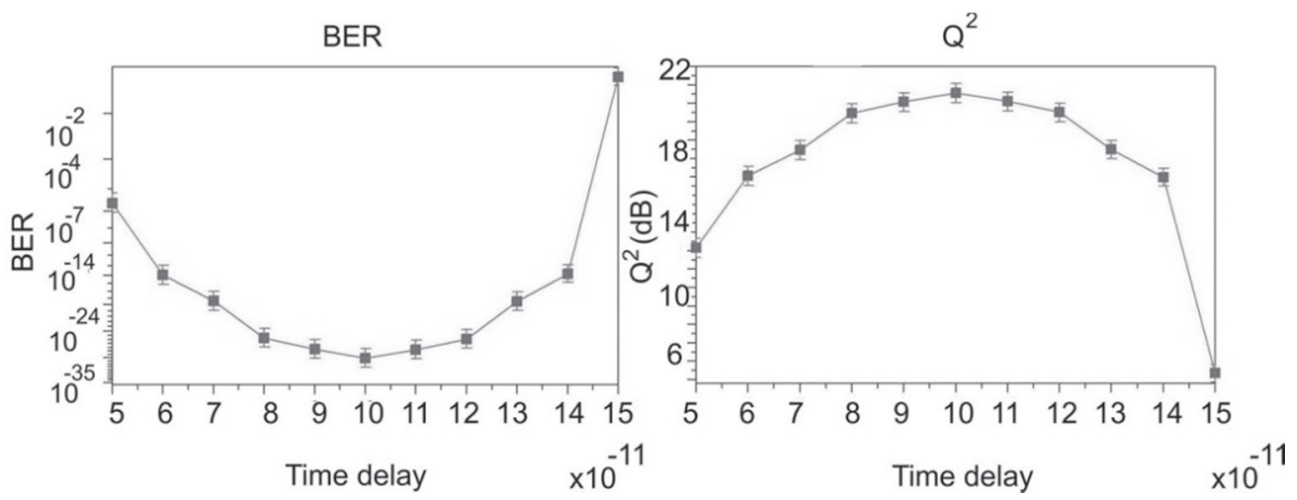

Figure 10 Comparison of BER and Q-factor for RZ-DPSK with increment 10 ps

\begin{tabular}{|c|c|c|c|c|}
\hline $\begin{array}{c}\text { Time delay } \\
{[\mathbf{p s}]}\end{array}$ & BER & BER lo & BER hi & $\mathbf{Q}^{\mathbf{2}}(\mathbf{d B})$ \\
\hline 50 & $2.4283^{-5}$ & $8.3219^{-6}$ & $6.6995^{-5}$ & 12.176 \\
\hline 60 & $1.0242^{-10}$ & $8.3101^{-12}$ & $1.1020^{-9}$ & 16.066 \\
\hline 70 & $3.7889^{-14}$ & $1.2157^{-15}$ & $9.7947^{-13}$ & 17.475 \\
\hline 80 & $2.5152^{-21}$ & $1.1414^{-23}$ & $4.1458^{-19}$ & 19.470 \\
\hline 90 & $3.0589^{-24}$ & $6.2464^{-27}$ & $1.0751^{-21}$ & 20.078 \\
\hline 100 & $6.8326^{-27}$ & $6.7953^{-30}$ & $4.7689^{-24}$ & 20.565 \\
\hline 110 & $2.1233^{-24}$ & $4.1708^{-27}$ & $7.8012^{-22}$ & 20.109 \\
\hline
\end{tabular}




\begin{tabular}{|l|l|l|l|l|}
\hline 120 & $1.4320^{-21}$ & $6.2521^{-24}$ & $2.4822^{-19}$ & 19.525 \\
\hline 130 & $3.4155^{-14}$ & $1.2492^{-15}$ & $7.9293^{-13}$ & 17.491 \\
\hline 140 & $1.4126^{-10}$ & $1.3872^{-11}$ & $1.2865^{-9}$ & 15.998 \\
\hline 150 & $3.2029^{-2}$ & $2.5422^{-2}$ & $3.9996^{-2}$ & 53.518 \\
\hline
\end{tabular}

Table 5 Result values of BER and Q- factor with increment 10 ps for RZ-DPSK

\section{Conclusion}

The aim of this article was the comparison between modulations with the same transfer speed for a particular channel. The end results were compared according to BER and Q-factor. DPSK gained worse results than RZ-DPSK. The second simulation with time delay shows the best usage of RZ-DPSK employing the delay of $100 \mathrm{ps}$ as opposed to DPSK where the difference is significant up to $10^{-9}$.

In optical transfer data systems a system is functioning if the measured BER parameter is not bigger than $10^{-12}$, and for that matter every larger delay cannot be used. For DPSK it is from 50 to130 ps and for RZ-DPSK it is from 70-130 ps.

\section{Acknowledgements}

This work was supported by research grant KEGA no. 023TUKE-4/2017.

\section{References}

[1] P. Ivaniga, T. Ivaniga, "10 Gbps optical line using EDFA for long distance lines“, Przeglad Elektrotechniczny, vol. 93, no.3, 2017, pp. 193-196.

[2] A. H. Gnuck, P. J. Wizner, "Optical Phase-Shift-Keyed Transmission", Journal of Lightwave technology, vol. 23, no. 1, 2005, pp. 115-130.

[3] J. Papán, P. Segeč, M. Drozdová, L. Mikuš, M. Moravčík, J. Hrabovský, "The IPFRR mechanism inspired by BIER algorithm," 2016 International Conference on Emerging eLearning Technologies and Applications (ICETA), 2016, pp. 257-262.

[4] M. Tatarko, J. Toth, L. Ovsenik, J. Turan, “Availability Measurement of Experimental FSO System, 2014, Proc. Of the $15^{\text {th }}$ Intern. Carpathian Control Conference, 2014, ISBN: 978-1-4799-3527-7, pp. 598-601.

[5] L'. Mikuš, "Evaluations of the error rate in backbone networks", Elektrorevue, vol. 12, no. 2, 2010, pp. 1-6.

[6] J. Ruzbarsky, J. Turan, L. Ovsenik, "Stimulated brillouin scattering in DWDM all optical communication systems", (2016), 2016, $26^{\text {th }}$ International Conference Radioelektronika, RADIOELEKTRONIKA 2016, art. no. 7477354, pp. 395-398. 
[7] Z. Lach, "Effect of Uncertain Reference Signal on Uncertainty of estimates of the First Order PMD in a Single Mode Optical Fibre", Przeglad Elektrotechniczny, vol. 92, no. 11, 2016, pp. 148-153.

[8] D. R. Pauluzzi, N. C. Beaulieu, "A Comparison of SNR Estimation Techniques for the AWGN Channel“", IEEE Transactions on, vol. 48, no. 10, 2000, pp.1681-1691.

[9] J. Smiesko, J. Uramova, “Access node dimensioning for IPTV traffic using effective bandwidth," Komunikacie, vol. 14, no. 2, 2012, pp. 11-16.

[10] L. Figuli, J. Smieško, "Recognition and Modelling of Bursty Period of Flow", WSEAS Transactions on Communications, vol.13, art. 49, 2014, pp. 444-451.

[11] A. Ghatak, K. Thyagarajan, "Fiber Optic Essentials", ISBN 978-0-47009742-7,2007, 259 pp.

[12] L. Ovsenik, J. Turan, M. Tatarko, M. Turan, J. Vásárhelyi, “Fog Sensor System: Design and Measurement, Proceedings of the $201213^{\text {th }}$

International Carpathian Control Conference, vol. 28, no. 31, 2012, pp. 529-532.

[13] W. Steingartner, D. Radaković, F. Valkošák, P. Macko, "Some properties of coalgebras and their rôle in computer science", In: Journal of Applied Mathematics and Computational Mechanic, vol. 15, no. 4, 2016, pp. 145156.

[14] T. Ivaniga, P. Ivaniga, "Comparison of the optical amplifiers EDFA and SOA based on the BER and Q-factor in C-band", Advances in Optical Technologies, doi:10.1155/2017/9053582, 2017, pp.1-9.

[15] J. Ruzbarsky, L. Ovsenik, J. Turan, "Effects Act on Transmitted Signal in a Fully Optical Fiber WDM Systems“, Informatics 2015. - Danvers: IEEE, 2015, 217-221.

[16] L. Mikuš, "LMS systém Moodle“, E-learn Žilina 2004, ISBN 80-8070190-3, 2004, pp. 243-248.

[17] J. Toth, M. Tatarko, L. Ovsenik, J. Turan, "Long term availability analysis of experimental free space optics system“, (2015) 2015 22nd International Conference on Systems, Signals and Image Processing - Proceedings of IWSSIP 2015, art. no. 7313929, pp. 29-32.

[18] L. Ovsenik, P. Filo, JR. J. Turan, J. Turan: “www - Based Remote Access to Engineering Laboratory“, TELSIKS - $7^{\text {th }}$ Intern. Conference on Telecommunications in Modern Satellite, vol. 1, 2005, pp. 39-44.

[19] P. Liptai, B. Dolník, M. Pavlík, J. Zbojovský, M. Špes “Check measurements of magnetic flux density: Equipment design and the 
determination of the confidence interval for EFA 300 measuring devices", Measurement, vol. 111, 2017, pp. 51-59.

[20] V. Skorpil, R. Precechtel, "Training a neural network for a new node element design“, Przeglad Elektrotechniczny, vol. 89, no. 2B, 2013, pp.187-192.

[21] J. Turán, L. Ovseník, "Experimental free space optics project", Proceedings of the 17th Symposium IMEKO TC4-Measurement of Electrical Quantities, Košice, 2010, pp. 431-434.

[22] P. Liptai, M. Moravec, E. Lumnitzer, K. Lukáčová, "Impact analysis of the electromagnetic fields of transformer stations close to residential buildings" In: SGEM 2014,vol. 1, 2014, pp. 355-360.

[23] W. Steingartner, V. Novitzká, “Categorical model of structural operational semantics for imperative language, Journal of Information and Organizational Sciences, vol. 40, no. 2, 2016, pp. 203-219.

[24] P. Ivaniga, L. Mikus, "Measuring of Block Error Rates in High-Speed Digital Networks", Advances in Electrical and Electronic Engineering, vol. 5, 2011, pp. 35-36.

[25] J. Smiesko, "Exponential model of token bucket system", Komunikacie, vol. 5 , no. 4 , pp. 66-70. 